\title{
Determinants of the Formalisation of Human Resource Management Practices: An Empirical Study in SMEs in Eastern and Western China
}

DOI:

10.1080/00472778.2019.1705663

\section{Document Version}

Accepted author manuscript

Link to publication record in Manchester Research Explorer

Citation for published version (APA):

LI, S., \& Rees, C. (2021). Determinants of the Formalisation of Human Resource Management Practices: An Empirical Study in SMEs in Eastern and Western China. Journal of Small Business Management, 59(4), 735-755. https://doi.org/10.1080/00472778.2019.1705663

Published in:

Journal of Small Business Management

\section{Citing this paper}

Please note that where the full-text provided on Manchester Research Explorer is the Author Accepted Manuscript or Proof version this may differ from the final Published version. If citing, it is advised that you check and use the publisher's definitive version.

\section{General rights}

Copyright and moral rights for the publications made accessible in the Research Explorer are retained by the authors and/or other copyright owners and it is a condition of accessing publications that users recognise and abide by the legal requirements associated with these rights.

\section{Takedown policy}

If you believe that this document breaches copyright please refer to the University of Manchester's Takedown Procedures [http://man.ac.uk/04Y6Bo] or contact uml.scholarlycommunications@manchester.ac.uk providing relevant details, so we can investigate your claim.

\section{OPEN ACCESS}


This pre-publication manuscript has been accepted by the Journal of Small Business Management. It has yet to be edited and proofread by the journal

\section{Li, S. \& Rees, C.J (2020)}

\section{Determinants of the Formalisation of Human Resource Management Practices: An Empirical Study in SMEs in Eastern and Western China}

This quantitative study examines the role of five contingency factors, that is, firm size, sector, location, firm age and presence of an HR department, in formalising human resource management (HRM) practices in small and medium-sized enterprises (SMEs) in eastern and western China. Using data from 227 respondents in 24 Chinese SMEs, the findings reveal a mixed pattern of relationships between these determinants and the actual formal use of five clusters of HRM practices. Location and presence of HR were found to exert stronger influence than size and sector. Theoretical and practical implications for HRM are discussed with reference to contingency factors in the SME sector in China.

\section{Introduction}

Small and medium-sized enterprises (SMEs) have been increasingly recognised as a powerful engine in economic growth and employment in both developed and developing economies (Tewari et al. 2013). China, a rapidly developing country, is currently at a transitional phase shifting from an agricultural and heavy manufacturing economy to a light industrial and service industrial economy (Cooke 2012; Warner 2009). Under such circumstances, SMEs have been placed in a complex and uncertain environment. The statistics show that SMEs account for 99 per cent of total registered business and 80 per cent of total employment (Cunningham 2011; Qiao, Wang, and Wei 2015). In order to maximise further their positive impact in the transition process, policymakers have been making increasing efforts to promote their development. Nevertheless, SMEs in China face challenges not only in accessing finance and markets, but also in effectively managing their workforces (Cooke 2012; Hooi and Ngui 2014). These human resource management (HRM) challenges include failing to attract, motivate and retain managerial and professional talents, high staff turnover rates, ignorance of HR planning processes, inadequate training and development provision, informal and subjective performance appraisals leading to unfair results, poorly designed and uncompetitive compensation packages, and negative employee perceptions of HRM practices (Bai, Yuan, and Pan 2016; Cooke 2012; Cunningham and Rowley 2008; Authors 2019; Paul, Parthasarathy, and Gupta 2017). Chu (2016, p. 64) concludes that there is an 
urgent need for SMEs in China to "update their management concepts and find more efficient management modes". Additional insights into how HRM practices are formalised would help SMEs to deal more effectively with these types of HRM challenges and thus contribute to the development of the SME sector in China.

A recent review suggests that the linkage between HRM and organisational performance, the influence of contextual factors (like Chinese culture) in HRM adoption, and the comparison between traditional Chinese management style and western management practices are three main foci in SMEfocused HRM research in China (Cunningham and Rowley 2010). Nevertheless, although there is growing interest in research into SMEs, HRM-related research in China remains relatively sparse. Existent literature is largely geographically biased, in that SMEs in relatively prosperous regions attract far more attention tan SMEs in less-developed areas such as western China, which remain under-researched (Cooke 2009; Warner and Rowley 2010). Thus, despite well-documented disparities in economic environment, local policies, the degree of openness, and market maturity between eastern / costal and western / inland China, little is known about the impact of regional differences on HRM adoption and formalisation (Ouyang, Liu, and Zhang 2016) thus leading to calls for research which contextualises HRM in China by examining regional disparities in HRM practices (Sheldon and Sanders 2016). For example, when recognising that their results on the effect of pay-for-performance schemes on SME performance in Canada may not be generalisable to other contexts, Wang, Thornhill, and Zhao (2018) specifically call for further HRM research involving collectivist cultures. Discussions of this nature relate directly to debates in HRM literature which explore the efficacy of contingent as opposed to universalistic approaches to HRM in organisational contexts, that is, whether there is primarily one 'best' universal way of conducting HRM in organisational settings or whether HRM is best understood, moderated, and applied in a manner which takes into account the various internal and external contingencies which prevail in a given context (Beer, Boselie, and Brewster 2015; Delery and Doty 1996; Farndale and Sanders 2017). Yet, while various studies have highlighted the value of research which sheds light on the influence of moderating contextual factors on HRM 'best' practice (Pudelko and Harzing 2007), this body of literature has tended to focus upon HRM and performance with reference to multi-national companies (MNCs) (Björkman, and Welch 2015; Schuler, Dowling, and De Cieri 1993). Thus, we aim to contribute to discussions surrounding contingency approaches to HRM by considering the influence of a predetermined set of contingencies on HRM practices in SMEs in China. For example, by determining the relative influence of these contingencies on HRM practices in this context, the findings have the potential to offer 
insights into the development of contingency frameworks which clarify the influence of moderating factors on HRM practice (Budhwar, Varma, and Patel 2016).

In summary, given the considerable economic contribution and potential impact of SMEs and the dearth of HRM research in this sector in China, there is a need for further research into how HRM practices in this context are informed. Therefore, the main aim of this paper is to examine the extent to which HRM practices in SMEs in China are influenced by a set of contingent factors, namely, firm size, sector, age, the presence of an HR department, and geographical location. Adopting the latest criteria stating in "Provisions on the Standards for SMEs", SMEs in this paper are defined as privately-owned firms that have less than 300 employees as 300 is applied to most sectors (PRC 2011).

\section{HRM Practices in SMEs}

Previous literature has suggested that SMEs are likely to employ informal, low-cost, reactive, short-term oriented, heterogeneous and emergent HRM practices (Cunningham 2010; Krishnan and Scullion 2017; Richbell, Szerb, and Vitai 2010). As such, some may argue that there is no need to formalise HRM practices in SMEs as the family-like relationships which are prevalent in these types of organisations foster flexibility and communication effectiveness and serve to minimise bureaucracy. However, evidence is emerging to indicate that some Chinese SMEs are moving towards a more marketdriven HRM approach due to the market-oriented economic transition and the growing participation of the Chinese economy in the global economy (Cunningham 2010). This then raises questions surrounding the factors which influence the adoption of HRM practices in the SME sector in China. Newman and Sheikh (2014, p. 415) conclude that: "there has been no examination of what determines the adoption of such practices (best HR practices)". Published HRM studies which have explored these adoption determinants in the Chinese context either included SMEs as a part of a wider sample (Ding, Akhtar, and Ge 2006; Kim and Gao 2010), or concentrated on contextual, institutional, and cultural elements (Cunningham 2010; Siu and Glover 2001). Exceptionally, work by Newman and Sheikh (2014) placed exclusive focus on the effcts of a series of organisational factors in Chinese SMEs including firm size, links with other organisations and government officials, and ownership. Yet, like the majority of existing studies, this work remains largely geographicallycentred. 
As this study attempts to examine how HRM practices in SMEs in China are influenced by a set of organisational factors, contingency theory provides an appropriate theoretical underpinning for the research as it highlights the contextualisation of HRM. This theory argues that there is no universally best way of HRM for an organisation, but rather suggests that the adoption of HRM practices is dependent on contingencies; consequently, the use of specific HRM practices in specific contexts is expected to maximise organisational performance (Delery and Doty 1996). Those contingencies can be interpreted broadly and range from national culture, industry, and region, to business strategy, processes, structure, and ownership (Akingbola 2012; Farndale and Sanders 2017).

Given the broad scope of potential contingencies, there is a need to be selective with reference to the context and design of a study. We selected five contingency factors that are associated with business characteristics including firm size, sector, location, presence of an HR department, and the age of the firm. The rationale for placing an exclusive focus on five organisational factors lies in three aspects. First, as stated in the arguments presented earlier, contingency theory provides a justification for exploring links between contingency factors, and HRM practices and performance; hence clarification of the role of contingency factors in influencing HRM practices can provide an insight into effective HRM in the SME sector. Second, institutional and cultural factors have attracted attention in the relatively limited body of Chinese SME literature (Cooke 2012; Cunningham 2010; Warner 2010). In contrast, organisational factors have, in the main, attracted relatively little attention other than as control variables. Third, while institutional and cultural diversity within the SME sector compounds the design complexity of international comparative studies, organisational factors such as the size and the age of the firm, have the potential to facilitate comparisons with SMEs in other emerging and developed economies. The reasons for selecting specific contingencies and the literature regarding their effect in different national settings are presented below in the discussion surrounding the development of hypotheses.

Firm size. Size is widely employed to define SMEs. Prior studies provide solid evidence to indicate that firm size is a key determinant of the formalisation of HRM practices in SMEs (Cunningham 2010; Gamage and Sadoi 2008; Garavan et al. 2016; Psychogios et al. 2016; Richbell, Szerb, and Vitai 2010; Storey et al. 2010). In an analysis of small firms in Australia, Kotey and Sheridan (2004, p. 483) highlighted that HRM practices are influenced by the size of the firm and become more standardised as the number of employees increases; these authors draw the conclusion that the size of the organisation must be made explicit for "...any meaningful analysis to be undertaken". In the Chinese context, Kim and Gao (2010) found that, based on a sample of 205 
family firms, firm size is a significant variable in predicting HRM formality. Likewise, Zheng, Morrison, and O’Neill's (2009) analysis of 74 SMEs with different ownership shows that firm size positively associates with the adoption of innovative HR practices. Contrary to these mainstream findings, there is other research which indicates no direct relationship between firm size and the adoption of HR practices (Urbano and Yordanova 2008). A recent Chinese SME study $(N=345)$ reports a complex relationship relating to firm size and the use of HR practices (Newman and Sheikh 2014); the findings indicate that size positively predicts the greater use of performance-related pay, induction and written HR policies while the employment of management training, performance appraisal system and job application forms does not differ between firms of different sizes. Similar observations of differing effects are also made by Fabi, Raymond, and Lacoursière (2007). Hence, although aspects of the relationship between firm size and HR practices have been examined in previous research, the nature of this relationship remains contested. Therefore, hypothesis 1 was developed and is presented below.

\section{Hypothesis 1: Firm size positively predicts the formalisation of HRM practices in SMEs in China.}

Sector. Sector is another influential factor which may explain variations in the adoption of HRM practices as homogeneity and heterogeneity within and across sectors can drive HRM practices to converge or diverge due to sectorial norms, standards, expectations and practices. (Psychogios et al. 2016; Tsai 2010). For example, a recent analysis indicates that the implementation of high-performance work practices (HPWPs) in small firms in the education, health and community sectors is relatively common when compared with implementation in small firms in the manufacturing sector (Wu, Bacon, and Hoque 2014). In a similar vein, Harney and Dundon's (2007) findings revealed that service SMEs are more likely to implement proactive and sophisticated HRM practices than those in the manufacturing sector as firms in the former sector require higher quality and frequency of delivering services. In relation to the Asian context, a comparative study based on a sample of $436 \mathrm{SMEs}$ found that recruitment, selection, training, compensation, and performance appraisals tend to be more formal in the service sector than in manufacturing SMEs (Raziq 2011). Similar observations are also made by Pattanaik, Mishra, and Dash (2017).

In the service sector, the enhancement of service quality is likely to depend on people who are directly involved in the service delivery process. As a result, the enhancement of service quality would require continuous investment in people by means such as the provision of professional training and development, attractive compensation packages and effective performance appraisals for retaining, motivating and growth 
(Wu, Bacon, and Hoque 2014). Therefore, in relation to SMEs in China, hypothesis 2 was developed and is presented below.

Hypothesis 2: SMEs in the service sector is more likely to adopt formal HRM practices than those in the manufacturing sector.

Location. This contingency is included due to the need to examine its effect and identify any regional differences within China. Geographical bases, resources and policy enforcement lead to notably wide variations in terms of economic, political and social conditions across regions in China. The uneven development of and variations in regional policies further contribute to disparities in attracting foreign investment and prevalence of market-oriented HRM (Ding, Akhtar, and Ge 2006). As such, the influence of geographic location on HRM practices is especially vague in the SME sector in China. Warner's (2010) research suggests an emerging form of market-oriented HRM model in SMEs in East China though the study does not include a comparison with SMEs in the western or inland regions. Similarly, Warner, Goodall, and Ding's (2002) study involving state-owned enterprises (SOEs, as opposed to SMEs) located in more northern and the more inland cities indicates that location exerts a significant effect on HRM patterns as these organisations are prone to adopt traditional approaches to people management. A recent survey based on a national sample with varying ownership revealed that enterprises located in coastal regions are more likely to adopt high-involvement human resource system than those in inland regions (Ouyang, Liu, and Zhang 2016). An exceptional observation was made by Kim and Gao (2010) who found no effect of location on HRM practices in a sample of 205 family firms in China.

Further, to compound the lack of clarity surrounding the relationship between location and HR practices, it is highlighted that Chinese SMEs' HRM studies tend to be geographically biased because developed coastal regions and large cities tend to feature more prominently in research samples whereas north-western inland regions are considerably underexplored (Cunningham and Rowley 2010). Thus, the effect of location on HR practices in SMEs in China remains contested. Given the vast territory of China and the considerably wide regional variations, the influence of location needs to be clarified to understand more fully the contingencies which are shaping HRM practices in this context. Therefore, hypothesis 3 was developed and is presented below.

Hypothesis 3: SMEs in more developed regions adopt more formal HRM practices. 
Presence of an HR department. This contingency is selected because, at a general level, it tends to indicate the formalisation of HRM in an organisation and how human resources and HRM are valued by owners (BayoMoriones, Galdon-Sanchez, and Martinez-De-Morentin 2013; Garavan et al. 2016; Storey et al. 2010). In the SME sector, HRM practices tend to be performed by owner-managers rather than by dedicated HR specialists working within an established $\mathrm{HR}$ department (Wu, Bacon, and Hoque 2014). Yet, in the SME, the extent to which the presence of professional HR staff and an HR department leads to the adoption of formal HR practices, is not clear as previous studies have resultein apparently contradictory results. For instance, a survey of SMEs in the UK and Republic of Ireland conducted by Garavan et al. (2016) found a positive relationship between the presence of HR expertise and the adoption of leadership development practices. In contrast, another UK-based study involving small firms $(N=298)$ found that the use of HPWPs was not related to the presence of HR specialists but associated with the access to external sources of HR advice (Wu, Bacon, and Hoque 2014). Given the variations in approaches to HRM in the SME sector in China and this lack of clarity surrounding the influence of the presence of HR professionals on HRM practices, hypothesis 4 was developed and is presented below.

Hypothesis 4: The presence of an HR department leads to greater use of formal HRM practices in SMEs.

Firm age. This contingency can indicate the organisational maturity and hence reflect the level of HRM, which is considered in this study as another potential explanatory influence on the formalisation of HRM practices. In general terms, firms with a longer operational history are prone to formalise HRM practices more than firms with a shorter operational history. SMEs are commonly characterised by short life-san, short-term orientation and informality (Cunningham 2010). As SMEs operate, they need to continuously cope with emerging issues related to internal management and external competitions in dynamic business environment for ensuring their growth, or at least survival, especially in transitional China where undergoing dramatic changes. Even though the relevance of HRM practices to relatively young SMEs has been emphasised in small business literature (Rauch and Hatak 2016), the management practices in the SMEs that remain or even develop over the years tend to be more sophisticated than the newly founded SMEs. De Kok, Uhlaner, and Thurik (2003) support this proposition when reporting that relatively young small firms employed more informal selection procedures. Opposing views state that younger firms tend to adopt more market-oriented, formal HRM approaches (Ding, Akhtar, and Ge 2006). Yet, there is also evidence to indicate that the age of a firm is not directly related to the formalisation of HR practices (Gamage and Sadoi 2008; Psychogios et 
al. 2016; Urbano and Yordanova 2008). Thus, the effect of the contingency of firm age on the formalisation of HRM remains unclear in the SME sector in China. Considering the transitional environment in the specific context, hypothesis 5 was developed and is reported below.

Hypothesis 5: Firm establishment age positively predicts the formalisation of HRM practices in SMEs.

In summary, drawing upon contingency theory, five hypotheses have been theoretically developed by concentrating the role of five specific contingencies in informing HRM practices in Chinese SMEs. Regarding the empirical evidence, the extant research either draws conclusions based on different national settings, or made no reference to SMEs, or merely included SMEs as a part of sample. Therefore, the five contingencies are studied in the Chinese SME sector in this research by adopting the methodology reported below.

\section{Methodology}

To address the five hypotheses stated above, a survey was conducted in two provinces in China, that is, Jiangsu and Shaanxi. These two provinces were selected as they represent eastern (costal) and western (inland) China. Given the reported difficulties in sampling SMEs in China, a snowball sampling method was used as this method has been widely employed in previous Chinese HRM studies (Cai, Morris, and Chen 2011; Cunningham 2010; Kim and Gao 2010). A set of criteria were followed for the selection of SMEs. They were: firm size less than 300 employees (PRC 2011); ownership is privately-owned as most SMEs are private firmsCunningham 2011); years of operation are at least three years to avoid newly founded SMEs; urban-based to reflect the profile of SMEs in China. Urban-based SMEs are taken to mean those SMEs which are registered and located in urban areas.

343 questionnaires were distributed to employees at different levels and departments in 24 SMEs including HR managers (or people who are in charge of HR), other senior and line managers, and shopfloor employees. Of the 284 returned questionnaires, 227 were valid, providing a response rate of 66 per cent. Although HR managers are assumed to be the key informants with the best knowledge of HR in their firms, they may provide information about intended HRM practices rather than actual practices as the former may not lead to the latter (Storey et al. 2010). The approach to data collection was designed to help determine whether HRM practices were in use and the extent of formality of these practices (Bos-Nehles and 
Veenendaal 2017). Further, the involvement of a range of respondents in one organisation can cross-validate the answers from different sources as due to the varied nature of work and hierarchical status within organisations, the content and formality of HRM practices may vary throughout the organisation. Hence, to capture a comprehensive and true picture of the HRM practices that are adopted and actually used in SMEs, an average of nine respondents were sampled in each SME $(S D=4.4)$. The average length of service of participants was 31.3 month $(S D=30.3) .79$ per cent of the respondents hold a professional college degree or above. 50 per cent of the sampled SMEs were in Jiangsu and the others were in Shaanxi Province. 62 per cent of the sample were in the service sector.

The questionnaire was developed based on literature focused HRM in SMEs, namely, Cunningham (2010); Kotey and Slade (2005), Nguyen and Bryant (2004), and Zheng, Morrison, and O’Neill (2006). Participants were asked to assess the use of HRM practices in their firms. A total number of 39 items measured the use of HRM practices covering basic HR functions including recruitment and selection (for example, job descriptions, selection techniques), training and development (for example, training needs, methods), performance appraisals (for example, work objectives setting, assessment rating scales), compensation (for example, pay level, pay adjustment) and HR planning. One example of an item is: "I was provided with an induction programme when I started my new job”. Five-point Likert scales were adopted to assess the items, with 1 indicating strongly disagree and 5 indicating strongly agree. The reliability test yielded a Cronbach's alpha value of 0.95 .

Some recommended procedural and statistical remedies were taken to address the issue of common method variance (CMV) (Podsakoff et al. 2003). First, to relieve participants' potential concerns, anonymity and confidentiality were guaranteed and envelopes were provided to ensure their completed questionnaires were returned anonymously. During the administration process, it was emphasised that there was no right or wrong answers and respondents were encouraged to respond honestly. Second, the results of Harman's single-factor test indicate that ten factors with eigenvalues greater than 1 emerged suggesting common method bias is unlikely to be a threat in this study (ibid 2003).

Exploratory factor analysis was conducted for items relating to HRM practices to identify groups of HRM practices and reduce the number of variables (Field 2013). With reference to the scree plot and eigenvalues greater than one (ibid 2013), a five-factor model was obtained, totally accounting for 52.4 per cent of variance. The rotated factor loadings were further analysed, indicating the factors were related to five HR domains which are: staffing, training and development (T\&D), performance management (PM), reward 
management (RM) and HR planning (HRP). The staffing factor reflects items focused upon recruitment, selection and induction practices. Reliability tests were then performed for these sub-scales and their coefficients were $0.84,0.91,0.76,0.86$ and 0.82 respectively. Dummies were created for the categorical variables including sector, location and presence of an HR department to be used as independent variables in the regression analysis.

\section{Results}

Pearson product-moment correlation tests and multiple regressions were performed to test hypotheses. Means, standard deviations and correlation coefficients of the variables are presented in Table 1. Significant relationships were found between: staffing and all explanatory variables except firm age; T\&D and sector and presence of HR; RM and presence of HR and firm age; HRP and sector and location. Unexpectedly, PM was not significantly related to any other variables.

[Take in table 1 here]

The results of multiple regression are presented in Table 2. Tolerance and variance inflation factor (VIF) were checked to diagnose multi-collinearity among variables. The value of tolerance was greater than 0.1 and VIF was less than 10 in all five models, indicating multi-collinearity is unlikely to be a problem in this study (Orme and Combs-Orme 2009). In general, all models had statistical significance except the PM model. The results of individual models are presented below.

Model 1 Staffing was predicted by size $(\beta=.168, p<.05)$ and presence of $\operatorname{HR}(\beta=.473, p<.001)$ but not by sector, location or firm age $(p>.05)$. The results suggested that SMEs were more likely to adopt formal staffing practices when the size was greater and an HR department was present. The comparison of $\beta$ coefficients further indicated that presence of HR had stronger predictive power than size in this model.

Model 2 Sector $(\beta=-.415, p<.01)$, location $(\beta=.367, p<.001)$ and presence of HR $(\beta=.184, p<.01)$ were predictors for $\mathrm{T} \& \mathrm{D}$ while size and firm age were not, suggesting $\mathrm{T} \& \mathrm{D}$ practices were more likely to be formalised in the SMEs with an HR department in the service sector in Jiangsu. Sector was the most important predictor in the model. 
Model 3 PM model had no statistical significance, suggesting none of the studied independent variables were predictors for PM practices.

Model $4 \mathrm{RM}$ indicated significant effects of location $(\beta=.21, p<.05)$, presence of $\mathrm{HR}(\beta=.183, p<.01)$ and firm age $(\beta=.297, p<.001)$ but non-significant effects of size or sector $(p>.05)$, suggesting more sophisticated RM practices were likely used in the SMEs located in Jiangsu, and when an HR department is present, and in older SMEs. Firm age was the strongest predictor, followed by location and presence of HR in the model.

Model 5 HRP was predicted by location $(\beta=.536, p<.001)$ and firm age $(\beta=.165, p<.05)$ while other dependent variables showed non-significant effects. The greater use of HRP practices was more likely in SMEs located in Jiangsu, and in older SMEs. Location was a more important predictor than age.

[Take in table 2 here]

In summary, all hypotheses are partly supported. $H 1$ size only positively predicted staffing practices. $H 2$ sector was a predictor of T\&D. $H 3$ location had a significant effect on T\&D, RM and HRP practices. $H 4$ presence of $H R$ was a significant explanatory variable for staffing, T\&D and RM practices. H5 firm age positively predicted RM and HRP practices.

\section{Discussion of Findings}

Although there have been increasing levels of research activity relating to HRM issues in China, such research has tended to focus on large organisations such as SOEs and MNCs; further, it has often sought to explore links between HR practices and organisational performance. Research which has explored the antecedents of HRM in the SME sector is relatively sparse and, when it has been conducted, has tended to omit inland areas of China. The current study has sought to address these gaps by examining the influence of five organisational factors on HRM practices in SMEs in western and estern China using a set of five hypotheses.

Overall, the results partly supported the hypotheses. Surprisingly, the size of the organisation $(H 1)$ only predicts the formal take-up of staffing practices. This finding tends to contradict the findings of most previous studies suggesting a significant correlation between size and the formalisation of wide range of HRM practices 
(Gamage and Sadoi 2008; Garavan et al. 2016; Kim and Gao 2010; Psychogios et al. 2016; Storey et al. 2010; Zheng, Morrison, and O’Neill 2009). We do not regard this to be counter-intuitive because, as SMEs expand, staffing tend to be the first field to be affected while other HR functions could be influenced only when new employees are in place. Besides, given that size interacts with numerous factors such as accessibility to resources and financial budget (Young-Thelin and Boluk 2012), the adoption and formalisation of HRM is unlikely to be informed solely by size but also by the interplay of various contextually relevant factors. Hence, given the variations and complexity within the SME sector, it is appropriate to question whether the contingency of firm size should be considered as a universally strong predictor of HRM formalisation as, is perhaps suggested by literature in other national settings and research findings generated from obtained SOEs, MNCs and joint ventures (JVs) in China.

Our findings also indicate that sector $(H 2)$ exerted a significant effect on formalising T\&D practices in SMEs in China. That is, based on the findings, SMEs in the service sector are more likely to formalise T\&D practices than those in the manufacturing sector. Thus, the findings support several previous studies such as $\mathrm{Wu}, \mathrm{Bacon}$, and Hoque (2014) and Harney and Dundon (2007) but run contrary to the findings of other studies (Garavan et al. 2016; Psychogios et al. 2016). As such, the conclusion we draw is that T\&D formalisation is the HR functional area which is most sensitive to the contingency of sector. This finding suggests that, from a relative perspective, the service sector may well be prioritising service quality and customer satisfaction as opposed to the manufacturing sector in which mechanisation and technology issues may, in the first instance, be prioritised. These distinct sector characteristics are likely to contribute to differing orientations in terms of investing in employees. One of the questions raised by this finding is whether the SME manufacturing sector in China is neglecting $\mathrm{T} \& \mathrm{D}$ in comparison to the service sector. However, sector is not a significant predictor of other HRM practices in our sample, implying its declining predictive strength in comparison to previous evidence which has suggested sector differences in overall HRM practices. The varying effect of sector may provide an indication that T\&D practices differentiate between these two sectors while other practices are less likely to be related to sector attributes in SMEs in China.

A further key finding reveals the effect of location $(H 3)$ on shaping T\&D, RM and HRP practices, that is, in our study, SMEs in Jiangsu are more likely to formalise T\&D, RM and HRP practices than SMEs in Shaanxi. This finding is not consistent with Kim and Gao's (2010) study in China which showed a nonsignificant effect of location on the formalisation of HRM practices. One possible explanation of this finding is that SMEs in Jiangsu are more influenced by foreign enterprises as the 
location offers access to advanced HRM knowledge and practices transferred by MNCs and JVs. In contrast to Shaanxi, Jiangsu also provides more potential opportunities to be involved in global economy. This influence of geographic location may also provide an indication of the differences in the level of economic development, labour market conditions, and demand-supply relations at the local level. More specifically, price level and income level are higher in Jiangsu compared to Shaanxi which would require RM to be more sophisticated in Jiangsu. Given that labour mobility tends to be greater in Jiangsu, the finding provides evidence that SMEs may need to put more efforts on T\&D and HRP to promote internal labour market and to predict the conditions of external labour market.

Previous HRM research focusing on China generally examines HRM issues at the national level by treating China as a homogenous country while locality has rarely been addressed (Sheldon and Sanders 2016). This finding relating to the contingency of location highlights the need to pay attention to differentiation and the diversity of HRM in China. It is reasonable to speculate that distinct patterns of HRM could exist at provincial, and even more local levels in China. This observation should serve as a note of caution regarding the use of phrases such as "Chinese HRM"; these types of phrases may represent over-simplifications and overgeneralisations. As such, location needs to be theoretically considered as a crucial contingency in shaping HRM practices, especially in the emerging economies with considerable variations across different regions.

Our study also found that the presence of an HR department $(H 4)$ shapes the formal adoption of staffing, T\&D and RM practices. Such a finding supports, in the main, the findings of Garavan et al. (2016) and Urbano and Yordanova's (2008) observation rather than the work of Wu, Bacon, and Hoque (2014). Although informality remains widespread in SMEs and such informality is not necessarily harmful (Krishnan and Scullion 2017; Storey et al. 2010), scholars have observed that increasing formality is likely to occur as SMEs grow and subsequently compete with larger firms in labour and product markets (Kotey and Folker 2007; Saridakis, Muñoz Torres, and Johnston 2013). As an indicator of formality, the hiring of HR professionals and the establishment of an HR department might be costly and superfluous for SMEs in the short-term, however, it would contribute to decreasing the risks of failure when formulating and implementing HRM policies and practices in the long-term. As such, this finding is likely to be relevant to SME owners who wish to formalise aspects of their HRM practices.

H5 Contrary to the assertion that newly founded SMEs tend to adopt more sophisticated HRM practices, possibly due to the growing awareness of the importance of HRM among new entrepreneurs (Ding, Akhtar, and Ge 2006; Wu, Bacon, and Hoque 2014), the findings of our study suggest that SMEs with a longer 
operational history are more likely to adopt formal RM and HRP practices. This finding is relatively intuitive given the transitional and uncertain environment in which Chinese SMEs are operating; SME owners may not be keen to employ sophisticated HRM practices at an early stage of the life of the SME unless they are confident on long-term operation and pay-off of investment in $\mathrm{HRM}(\mathrm{Wu}, \mathrm{Bacon}$, and Hoque 2014). Alternatively, as the longevity of SMEs increases, owners may perceive a necessity to formalisation to tackle emerging HRM issues. When seeking to interpret this finding, it is important to note the work of Rutherford, Buller, and McMullen (2003, p. 321 they report that: "firm age did not emerge as a significant indicator of stage-the firms' HR problems varied across stages defined by growth". This growth perspective is helpful as it highlights that the HR problems of SMEs are more dependent upon the growth of the SME than on its age. Yet our finding leads us to speculate whether the age of SMEs, rather than their growth, is influencing owners to adopt more sophisticated HRM practices. While more research is needed to examine the nature of the interaction between the adoption of sophisticated HRM practices, and contingencies relating to the growth and age of SMEs, this finding of our study offers clear support for Rutherford, Buller, and McMullen's (2003, p. 332) assertion that SME owner/managers should be encouraged to anticipate HRM problems and changes to HRM requirements if and when growth occurs.

\section{Summary and Conclusion}

This study adds knowledge to the literature by explaining how five contingency factors shape the formalisation of HRM practices in privately-owned SMEs in eastern and western China. We found a mixed pattern of relationships between the factors and the degree of formalisation of five clusters of HRM practices in the studied context, thus highlighting the complexity of the relationships. As such, our study aligns with contingency theory by demonstrating that the five factors have a shaping role which informs the adoption of HRM practices in Chinese SMEs. The findings regarding the varying predictive power of contingencies reveal that location and presence of an HR department are more important predictors than size and sector. Given that HRM contingency theory: “...suggests that the way that best practices are applied should be conditional upon the type of employee and on organisational setting (e.g. size of firms)" (Saridakis, Lai, and Cooper 2017, p. 90), our research further extends the theory by providing evidence that not all contingencies take effect concurrently in the same way and this should be taken into account by those who are seeking to develop contingency frameworks designed to represent and inform HRM practice in the SME sector in China. 
In relation to the study context, the findings reveal that the five contingency factors tend to exert an impact on several HRM practices rather than all. Given that contingency theory adopts a somewhat 'best fit' approach, we argue, based on our findings, for the desirability of combining contingency theory with a 'best practices' approach in this context. When studying the role of geographic context in the relationship between HRM and organisational performance, we draw attention to the fact that the notion of combining two approaches has been discussed and is empirically supported with reference to, for example, the European region (Stavrou, Brewster, and Charalambous 2010). Our findings build on this perspective with reference to the context of China. That is, to improve HRM effectiveness in the SME sector in China, the findings raise theossibility of developing a hybrid approach which recognises the HRM practices that are sensitive to contingency factors alongside the HRM 'best practices' which are not necessarily sensitive to contingencies but are being internationally recognised and applied. Such a hybrid approach may, at a theoretical level, go a way to addressing the complexity of the study context and could equally be applied to other transitional economies where contingency factors which influence HRM have been explored (Adnan, Abdullah, and Ahmad 2016; Ogunyoni and Bruning 2016).

The mixed pattern of relationships between the contingency factors and the degree of formalisation of five clusters of HRM practices also underscores the potential merit of further developing an eclectic approach, which synthesises elements from a wider range of perspectives, such as national cultural theory and institutional theory, to explain these variations (Farndale and Sanders 2017). For example, evidence suggests that staffing, T\&D, RM, and especially PM practices are greatly influenced by Chinese culture highlighting the importance of harmony, preservation of face, collective orientation and personal relationship (Cunningham 2010; Warner 2010). Arguably, staffing practices are more likely to be influenced by institutional forces, such as the condition of the labour market, than by contingencies such as sector, location and firm age. Similarly, RM practices tend to be regulated by labour legislation and may possibly have less association with contingencies such as size and sector (Cooke 2012; Cunningham and Rowley 2008). As such, our findings resonate with the statement that there is a: “...need for caution in applying any assumption that certain HRM practices, if standardized across territories, would be linked to similar competitive outcomes everywhere" (Stavrou, Brewster, and Charalambous 2010, p. 953).

In terms of practical implications, this paper should be of interest to SMEs owners/managers and HR practitioners who are keen to develop HRM system and strengthen the implementation of HRM practices in their firms. Specifically, the finding regarding the effect of sector on T\&D practices serves as a reminder that 
SMEs need to be selective when formalising their T\&D practices to reflect specific characteristics of the contexts in which they are operating. Although informality may provide greater flexibility for SMEs, this study also provides empirical evidence of the tendency of SMEs in this sector to increase formality in HRM alongside the longevity of the organisation. While this tendency further rationalises the use of HRM practices in this sector, care needs to be exercised by owners to ensure that this formality addresses the HRM requirements associated with the growth stage of the organisation. Hiring HR specialists and setting up an HR department might facilitate SMEs owners/managers and HR practitioners to formalise their staffing, T\&D and RM practices.

Finally, there are two main limitations associated with this study. First, we have placed a selective focus on specific organisational factors while not directly considering other factors such as the influence of institutions, national culture, international organisations, and the business environment. We recognise that other literature has sought to examine the influence of, for example, institutional and cultural elements on the adoption of HRM practices (Cunningham 2010; Siu and Glover 2001). Future research could examine additional factors and further compare the strength of the effect of other determinates. Such comparison would be helpful to develop an applied HRM framework in the Chinese context. Second, given that China is a huge country with great diversity, another limitation is the sample size. However, this study attempts to contribute to understanding about how organisational factors shape HRM practices in SMEs by sampling both eastern and western China rather than by generalising the results to the whole country; as a result, the current work has provided a number of valuable indications of the distinctiveness of these two locations. Nevertheless, we recognise the need for further multi-level comparative studies with larger samples to shed further light on the location effect highlighted in our findings. Further research could also examine how contingencies interact with each other andhether and how this interaction impacts on HRM choices.

\section{References}

Adnan, Z., H.S. Abdullah, and J. Ahmad (2016). "Assessing the Moderating Effect of Competition Intensity on HRM Practices and Organizational Performance Link: The Experience of Malaysian R\&D Companies," Procedia Economics and Finance 35(1), 462-467.

Akingbola, K. (2013). "Contingency, Fit and Flexibility of HRM in Nonprofit Organizations," Employee Relations 35(5), 479-494.

Bai, Y., J. Yuan, and J. Pan (2016). "Why SMEs in Emerging Economies are Reluctant to Provide Employee Training: Evidence from China," International Small Business Journal 35(6), 751-766.

Bayo-Moriones, A., J.E. Galdon-Sanchez, and S. Marinez-De-Morentin (2013). "The Diffusion of Pay for Performance across Occupations," ILR Review 66(5), 1115-1148.

Beer, M., P. Boselie, and C. Brewster (2015). "Back to the Future: Implications for the Field of HRM of the Multi-stakeholder Perspective Proposed 30 Years Ago," Human Resource Management, 54 (3), 427-438. 
Björkman, I. and D. Welch (2015). "Framing the Field of International Human Resource Management Research," The International Journal of Human Resource Management 26(2), 136-150.

Bos-Nehles, A.C., and A.A. Veenendaal (2017). "Perceptions of HR Practices and Innovative Work Behavior: The Moderating Effect of an Innovative Climate," The International Journal of Human Resource Management, 1-23.

Budhwar, P.S., A. Varma, and C. Patel (2016). "Convergence-divergence of HRM in the Asia-Pacific: Contextspecific Analysis and Future Research Agenda," Human Resource Management Review 26(4), 311-326.

Cai, Z., J.L. Morris, and J. Chen (2011). "Explaining the Human Resource Management Preferences of Employees: A Study of Chinese Workers," The International Journal of Human Resource Management 22(16), 3245-3269.

Chu, J. (2016). "Human Resource Management Outsourcing Decision for Small and Medium-Sized Enterprises in China," International Business Research 9(8), 64-71.

Cooke, F.L. (2009). "A Decade of Transformation of HRM in China: A Review of Literature and Suggestions for Future Studies," Asia Pacific Journal of Human Resources 47(1), 6-40.

Cooke, F.L. (2012). Human Resource Management in China: New Trends and Practices. Abingdon, UK: Routledge.

Cunningham, L.X. (2010). "Managing Human Resources in SMEs in a Transition Economy: Evidence from China," The International Journal of Human Resource Management 21 (12), 2120-2141.

Cunningham, L.X. (2011). "SMEs as Motor of Growth: A Review of China's SMEs Development in Thirty Years (1978-2008)," Human Systems Management 30(1-2), 39-54.

Cunningham, L.X., and C. Rowley (2008). "The Development of Chinese Small and Medium Enterprises and Human Resource Management: A Review," Asia Pacific Journal of Human Resource 46(3), 353-379.

Cunningham, L.X., and C. Rowley (2010). "Small and Medium-sized Enterprises in China: A Literature Review, Human Resource Management and Suggestions for Further Research," Asia Pacific Business Review 16(3), 319-337.

De Kok, J.M.P., L.M. Uhlaner, and A.R. Thurik (2003). "Human Resource Management with Small and Medium-sized Enterprises: Facts and Explanations," ERIM Report Series ERS 2003-015, Rotterdam: Erasmus University.

Delery, J.E., and D.H. Doty (1996). "Modes of Theorizing in Strategic Human Resource Management: Tests of Universalistic, Contingency, and Configurational Performance Predictions," Academy of Management Journal 39(4), 802-835.

Ding, D.Z., S. Akhtar, and G.L. Ge (2006). "Organizational Differences in Managerial Compensation and Benefits in Chinese Firms," The International Journal of Human Resource Management 17(4), 693-715.

Fabi, B., L. Raymond, and R. Lacoursière (2007). "HRM Practice Clusters in Relation to Size and Performance: An Empirical Investigation in Canadian Manufacturing SMEs," Journal of Small Business and Entrepreneurship 20(1), 25-39.

Farndale, E., and K. Sanders (2017). "Conceptualizing HRM System Strength through a Cross-Cultural Lens," The International Journal of Human Resource Management 28(1), 132-148.

Field, A. (2013). Discovering Statistics Using IBM SPSS Statistics, $4^{\text {th }}$ edition. London, UK: Sage.

Gamage, A., and Y. Sadoi (2008). "Determinants of Training and Development Practices in SMEs: A Case of Japanese Manufacturing Firms," Sri Lankan Journal of Human Resource Management 2(1), 46-61.

Garavan, T., S. Watson, R. Carbery, and F. O’Brien (2016). "The Antecedents of Leadership Development Practices in SMEs: The Influence of HRM Strategy and Practice," International Small Business Journal 34(6), 870-890.

Harney, B., and T. Dundon (2007). "An Emergent Theory of HRM: A Theoretical and Empirical Exploration of Determinants of HRM among Irish Small-to Medium-sized Enterprises (SMEs)," Advances in Industrial and Labor Relations 15, 103-153.

Hooi, L.W., and K.S. Ngui (2014). "Enhancing Organizational Performance of Malaysian SMEs: The Role of HRM and Organizational Learning Capability," International Journal of Manpower 35(7), 973-995.

Kim, Y., and F.Y. Gao (2010). "An Empirical Study of Human Resource Management Practices in Family Firms in China," The International Journal of Human Resource Management 21(12), 2095-2119. 
Kotey, B., and C. Folker (2007). "Employee Training in SMEs: Effect of Size and Firm Type-Family and Nonfamily," Journal of Small Business Management 45(2), 214-238.

Kotey, B., and A. Sheridan (2004). "Changing HRM Practices with Firm Growth," Journal of Small Business and Enterprise Development 11(4), 474-485.

Kotey, B., and P. Slade (2005). "Formal Human Resource Management Practices in Small Growing Firms," Journal of Small Business Management 43(1), 16-40.

Krishnan, T.N., and H. Scullion (2017). "Talent Management and Dynamic View of Talent in Small and Medium Enterprises," Human Resource Management Review 27(3), 431-441.

Newman, A., and A.Z. Sheikh (2014). "Determinants of Best HR Practices in Chinese SMEs," Journal of Small Business and Enterprise Development 21(3), 414-430.

Nguyen, T.V., and S.E. Bryant (2004). "A Study of the Formality of Human Resource Management Practices in Small and Medium-size Enterprises in Vietnam," International Small Business Journal 22(6), 595-618.

Ogunyomi, P. and N.S. Bruning (2016). "Human Resource Management and Organizational Performance of Small and Medium Enterprises (SMEs) in Nigeria," The International Journal of Human Resource Management 27(6), 612-634,

Orme, J.G., and T. Combs-Orme (2009). Multiple Regression with Discrete Dependent Variables. New York, NY: Oxford University Press.

Ouyang, C., X. Liu, and Z. Zhang (2016). "Organizational and Regional Influences on the Adoption of HighInvolvement Human Resource Systems in China: Evidence from Service Establishments," The International Journal of Human Resource Management 27(18), 2058-2074.

Pattanaik, B.K., S. Mishra, and M. Dash (2017). "Training for Development: A Comparative Analysis of Employees on Service and Industrial Sector," International Journal of Economic Research 14(10), 1-5.

Paul, J., S. Parthasarathy, and P. Gupta (2017). "Exporting Challenges of SMEs: A review and Future Research Agenda," Journal of World Business 52(3), 327-342.

People's Republic of China (PRC) (2011). "Provisions on the Standards for SMEs," available at: www.gov.cn/zwgk/2011-07/04/content_1898747.htm. Accessed on September 9, 2018.

Podsakoff, P.M., S.B. MacKenzie, J. Lee, and N.P. Podsakoff (2003). "Common Method Biases in Behavioral Research: A Critical Review of the Literature and Recommended Remedies," Journal of Applied Psychology 88(5), 879-903.

Psychogios, A.G., L.T. Szamosi, R. Prouska, and C. Brewster (2016). "A Three-fold Framework for Understanding HRM Practices in South-Eastern European SMEs,” Employee Relations 38(3), 310-331.

Pudelko, M., and A. Harzing (2007). "Country-of-Origin, Localization, or Dominance Effect? An Empirical Investigation of HRM," Human Resource Management, 46(4), 535-559.

Qiao, K., X. Wang, and L. Wei (2015). "Determinants of High Performance Work Systems in Small and Medium Sized Enterprises in China," Asia Pacific Journal of Human Resources 53(2), 185-203.

Rauch, A., and I. Hatak (2016). "A Meta-analysis of Different HR-enhancing Practices and Performance of Small and Medium Sized Firms," Journal of Business Venturing 31, 485-504.

Raziq A. (2011). "High Performance Management Practices in Manufacturing and Service-Based SMEs. A comparative Study," in Proceedings of the 24th Annual Conference of the Small Enterprise Association of Australia and New Zealand. Small Enterprise Association of Australia and New Zealand, 114-137.

Richbell, S., L. Szerb, and Z. Vitai (2010). "HRM in the Hungarian SME Sector," Employee Relations 32(3), 262-280.

Rutherford, M.W., P.F. Buller, and P.R. McMullen (2003). "Human Resource Management Problems over the Life Cycle of Small to Medium-sized Firms", Human Resource Management 42(4), 321-335.

Saridakis, G., Y. Lai, and C.L. Cooper (2017). "Exploring the Relationship between HRM and Firm Performance: A Meta-analysis of Longitudinal Studies," Human Resource Management Review 27(1), 8796.

Saridakis, G., R. Muñoz Torres, and S. Johnston (2013). "Do Human Resource Practices Enhance Organizational Commitment in SMEs with Low Employee Satisfaction?" British Journal of Management 24(3), 445-458.

Schuler, R.S., P.J. Dowling, and H. De Cieri (1993). “An Integrative Framework of Strategic International Human Resource Management," The International Journal of Human Resource Management 4(4), 717-764. 
Sheldon, P., and K. Sanders (2016). "Contextualising HRM in China: Differences within the Country," The International Journal of Human Resource Management 27(18), 2017-2033.

Siu, N.Y.M., and L. Glover (2001). "Barriers to Effective Managerial Practices in China," Asia Pacific Business Review 7(3), 57-74.

Stavrou, E.T., C. Brewster, and C. Charalambous (2010). "Human Resource Management and Firm Performance in Europe through the Lens of Business Systems: Best Fit, Best Practice or Both?" The International Journal of Human Resource Management 21(7), 933-962.

Storey, D.J., G. Saridakis, S. Sen Gupta, P.K. Edwards, and R.A. Blackburn (2010). "Linking HR Formality with Employee Job Quality: The Role of Firm and Workplace Size," Human Resource Management 49(2), 305-329.

Tewari, P.S., D. Skilling, P. Kumar, and Z. Wu (2013). Competitive Small and Medium Enterprises: A Diagnostic to Help Design Smart SME Policy. Washington, DC: World Bank.

Tsai, C. (2010). "HRM in SMEs: Homogeneity or Heterogeneity? A Study of Taiwanese High-tech Firms," The International Journal of Human Resource Management 21(10), 1689-1711.

Urbano, D., and D. Yordanova (2008). "Determinants of the Adoption of HRM Practices in Tourism SMEs in Spain: An Exploratory Study," Service Business 2(3), 167-185.

Wang, T., S. Thornhill, and B. Zhao (2018). "Pay-for-Performance, Employee Participation, and SME Performance," Journal of Small Business Management 56(3), 412-434.

Warner, M. (2009). "Making Sense' of HRM in China: Setting the Scene," The International Journal of Human Resource Management 20(11), 2169-2193.

Warner, M. (2010). "In Search of Confucian HRM: Theory and Practice in Greater China and Beyond," The International Journal of Human Resource Management 21(12), 2053-2078.

Warner, M., K. Goodall, and D.Z. Ding (2002). "Implementing China's People-management Reforms", in Managing across Cultures: Issues and Perspectives, $2^{\text {nd }}$ edition. Ed. M. Warner, and P. Joynt. London, UK: Thomson Learning, 168-177.

Wu, N., N. Bacon, and K. Hoque (2014). "The Adoption of High Performance Work Practices in Small Businesses: The Influence of Markets, Business Characteristics and HR Expertise," The International Journal of Human Resource Management 25(8), 1149-1169.

Young-Thelin, L., and K. Boluk (2012). "A Case Study of Human Resource Practices in Small Hotels in Sweden," Journal of Human Resources in Hospitality \& Tourism 11(4), 327-353.

Zheng, C., M. Morrison, and G. O’Neill (2006). "An Empirical Study of High Performance HRM Practices in Chinese SMEs," The International Journal of Human Resource Management 17(10), 1772-1803.

Zheng, C., M. Morrison, and G. O’Neill (2009). "Enhancing Chinese SME Performance through Innovative HR Practices," Personnel Review 38(2), 175-194.

Descriptive Statistics and Pearson Product-Moment Correlation Coefficients

\begin{tabular}{|c|c|c|c|c|c|c|c|c|c|c|}
\hline & 1 & 2 & 3 & 4 & 5 & 6 & 7 & 8 & 9 & 10 \\
\hline 1. Size & 1 & & & & & & & & & \\
\hline 2. Sector & $.644^{* *}$ & 1 & & & & & & & & \\
\hline 3. Location & $.355^{* *}$ & $.729^{* * *}$ & 1 & & & & & & & \\
\hline 4. Presence of HR & $.303^{* *}$ & $.169^{*}$ & $.258^{* *}$ & 1 & & & & & & \\
\hline 5. Firm age & $.404^{* *}$ & $.175^{* *}$ & -.072 & .109 & 1 & & & & & \\
\hline 6. Staffing & $.342^{* *}$ & $.262^{* *}$ & $.276^{* *}$ & $.544^{* *}$ & .090 & 1 & & & & \\
\hline
\end{tabular}




\begin{tabular}{|c|c|c|c|c|c|c|c|c|c|c|}
\hline 7. $T \& D$ & -.105 & $-.132^{*}$ & .104 & $.202^{* *}$ & -.090 & .067 & & & & \\
\hline 8. PM & -.013 & .104 & .120 & -.085 & .036 & .072 & .037 & & & \\
\hline 9. $\mathrm{RM}$ & .002 & -.014 & .070 & $.199^{* * *}$ & $.215^{* *}$ & .052 & .092 & .050 & & \\
\hline 10. HRP & .040 & $.225^{* *}$ & $.406^{* *}$ & .127 & .046 & .022 & .090 & .025 & .003 & 1 \\
\hline Mean & 100.62 & .38 & .50 & .79 & 10.21 & .000 & .000 & .000 & .000 & .000 \\
\hline SD & 99.498 & .495 & .511 & .415 & 4.681 & .877 & .908 & .886 & .882 & .896 \\
\hline
\end{tabular}

Notes: **. Correlation is significant at the 0.01 level (2-tailed). *. Correlation is significant at the 0.05 level (2-tailed). $N=227$.

Sector $($ service $=0$; manufacturing $=1)$; Location $($ Shaanxi $=0$; Jiangsu $=1)$; Presence of HR $($ absent $=0$; present $=1)$.

Table 2

Results of the Multiple Regressions on HRM Practices

\begin{tabular}{|c|c|c|c|c|c|c|c|c|c|}
\hline \multirow{3}{*}{$\begin{array}{l}\text { Variables } \\
\text { Size }\end{array}$} & \multirow{2}{*}{$\frac{\text { Model 1 }}{\beta}$} & \multirow{2}{*}{$\frac{\text { Staffing }}{t}$} & \multicolumn{2}{|c|}{ Model 2 T\&D } & \multirow{2}{*}{\multicolumn{2}{|c|}{ 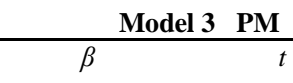 }} & \multirow{2}{*}{\multicolumn{2}{|c|}{$\begin{array}{lr}\text { Model 4 } & \text { RM } \\
\beta & t\end{array}$}} & \multirow{2}{*}{$\frac{\text { Model } 5 \text { HF }}{\beta}$} \\
\hline & & & $\beta$ & $t$ & & & & & \\
\hline & .168 & $2.062^{*}$ & -.023 & -.246 & -.120 & -1.221 & -.147 & -1.563 & -.169 \\
\hline Sector & .026 & .252 & -.415 & $-3.515^{* *}$ & .085 & .680 & -.156 & -1.308 & -.092 \\
\hline Location & .073 & .833 & .367 & $3.650^{* * *}$ & .136 & 1.282 & .210 & $2.073^{*}$ & .536 \\
\hline Presence of HR & .473 & $7.908^{* * *}$ & .184 & $2.696^{* *}$ & -.108 & -1.494 & .183 & $2.652^{* *}$ & .037 \\
\hline Firm age & -.028 & -.454 & -.002 & -.027 & .091 & 1.214 & .297 & $4.143^{* * *}$ & .165 \\
\hline Adjusted $R^{2}$ & .324 & & .113 & & .017 & & .097 & & .185 \\
\hline$F$ & $22.640^{* * *}$ & & $6.751^{* * *}$ & & 1.796 & & $5.852^{* * * *}$ & & $11.240^{* * *}$ \\
\hline
\end{tabular}

Notes: Standardised $\beta$ coefficients are reported. * $p<0.05 ; * * p<0.01 ; * * *<0.001$.

Sector $($ service $=0$; manufacturing $=1)$; Location $($ Shaanxi = 0; Jiangsu $=1)$; Presence of HR $($ absent $=0$; present $=1)$. 